\title{
FUNCTIONALISED SOLVENTS FOR OLEFIN ISOMER PURIFICATION BY REACTIVE EXTRACTIVE DISTILLATION
}

\author{
Norbert J. M. Kuipers ${ }^{1}$, Annebart E. Wentink ${ }^{1}$, Andre B. de Haan ${ }^{1}$, Japie Scholtz ${ }^{2}$, \\ Harko Mulder ${ }^{2}$ \\ ${ }^{1}$ Faculty of Science and Technology, University of Twente, PO Box 217, 7500 AE Enschede, \\ The Netherlands \\ ${ }^{2}$ Sasol Technology, Sasolburg, South Africa. E-mail: n.j.m.kuipers@utwente.nl
}

Olefin isomer separations are difficult, energy intensive and thus expensive. An overview is presented to investigate the feasibility of metal-ligand complexes as functionalized solvents applied in a novel separation technology, Reactive Extractive Distillation, for the separation and purification of $\alpha$-olefins like 1-hexene from other C6-olefin isomers (internal, branched, cyclic and diolefins) and paraffins by using $\pi$-complexation. Functionalized metal-ligand complexes were synthesized based on commercial available ligands from hydrometallurgy. In screening experiments they were evaluated for $\pi$-complexation with ethylene. The best solvents were selected for evaluation of preferential complexation of 1-hexene relative to other olefin isomers. Di (2-ethylhexyl)phosphoric acid (D2EHPA) and di-nonyl naphthalene sulphonic acid (DNNSA) yield both stable metal-ligand complexes and triple the solubility of ethylene. Next, three different phosphoric acid ligands: di (2-ethylhexyl) phosphoric acid (D2EHPA), di (butyl) phosphoric acid (DBPA) and mono (2-ethylhexyl) phosphoric acid (MEHPA) and two sulphonic acid ligands: di-nonyl naphthalene sulphonic acid (DNNSA) and dodecyl benzene sulphonic acid (DBSA), were investigated for a variety of C6-olefin isomers (1-hexene, 2-methyl-1-pentene, n-hexane, 1,5-hexadiene, trans-2-hexene). The highest selectivities were obtained for silver-DBPA (20 wt $\% \mathrm{Ag}, S / F=3$ ): 1.23 for 2-methyl-1pentene and 1.42 for $\mathrm{n}$-hexane.

A thermodynamic model is used to conceptually design a Reactive Extractive Distillation column applying the functionalised solvent silver-D2EHPA. Such a column should be operated at a solvent to feed ratio of around 5 ( $p=0.2 \mathrm{bar}, T=311 \mathrm{~K}$ ) for $99.5 \%$ purity and $99 \%$ recovery. Under these conditions, the minimum number of equilibrium trays $\left(N_{\min }\right)$ to separate 1-hexene from 2-methyl-1-pentene is approximately 42 , a dramatic decrease compared to $N_{\min }$ of about 310 in the absence of silver.

KEYWORDS: reactive extractive distillation, $\pi$-complexation, ligands, olefin isomer separation

\section{INTRODUCTION}

Olefin isomer separations are difficult, energy intensive and thus expensive. Objective is to explore the feasibility of metal-ligand complexes as functionalised solvents applied in Reactive Extractive Distillation for purification of $\alpha$-olefins like 1-hexene from other C6-olefin isomers (internal, branched, cyclic and diolefins) and paraffins, as typically present in Fischer Tropsch streams (Table 1), by exploiting $\pi$-complexation. 
In Reactive Extractive Distillation two or more isomers (A and B) are separated by distillation by means of a difference in reactivity with the affinity solvent $S$, as depicted in Figure 1a. The feasibility of suitable metal-ligand complexes is evaluated according to the ability of the ligand to keep the metal in solution while the latter retains its ability for selective $\pi$-complexation with an olefin, see Figure $1 b$.

The focus is on the selection and evaluation of functionalized solvents for a maximum achievable selectivity based on phase and reaction equilibria and using commercial available ligands. Four topics are discussed:

1. The influence of molecular structure of the olefin (cyclic, branched, internal) as well as its concentration, the silver concentration and the temperature on the solvent selectivity. This is investigated by liquid-liquid extraction experiments using an $\mathrm{AgNO}_{3}$ solution and a solution of a single C6-olefin isomer in n-hexane.

2. Screening and selection of metal-ligand complexes by measuring the (equilibrium) solubility of ethylene in these solvents in an Intelligent Gravimetric Analyser using ligands from hydrometallurgical applications.

3. Evaluation of the successfully developed metal-ligand complexes in a VLE set-up for a high vapour-liquid selectivity and capacity of the $\alpha$-olefin over other olefin isomers

Table 1. Simplified composition of C6-cut from Fischer-Tropsch stream and relative volatility (RV) to 1-hexene at $300 \mathrm{~K}$

\begin{tabular}{|c|c|c|c|c|}
\hline $\begin{array}{l}\text { Olefin } \\
\text { type }\end{array}$ & $\begin{array}{l}\text { wt } \% \text { in } \\
\text { C6-cut }\end{array}$ & $\begin{array}{c}\text { Model } \\
\text { component }\end{array}$ & Structure & $\begin{array}{l}\text { Relative volatility } \\
\qquad\left(\mathrm{P}_{\mathrm{vpi}} / \mathrm{P}_{\mathrm{vp} 1 \mathrm{H}}\right)\end{array}$ \\
\hline$\alpha$-Olefin & 58.6 & 1-hexene & & 1.00 \\
\hline $\begin{array}{l}\text { Branched } \\
\text { olefin }\end{array}$ & 22.9 & 2-methyl-1-pentene & & 1.06 \\
\hline $\begin{array}{r}\text { Internal } \\
\text { olefin }\end{array}$ & 2.2 & $\begin{array}{l}\text { 2-hexene } \\
\text { (cis or trans) }\end{array}$ & & $0.81,0.84$ \\
\hline $\begin{array}{l}\text { Cyclic } \\
\text { olefin }\end{array}$ & 1.7 & 1-methylcyclopentene & & 0.63 \\
\hline Diolefin & 0.03 & 1,5-hexadiene & & 1.20 \\
\hline Paraffin & 14.6 & n-hexane & & 0.82 \\
\hline
\end{tabular}




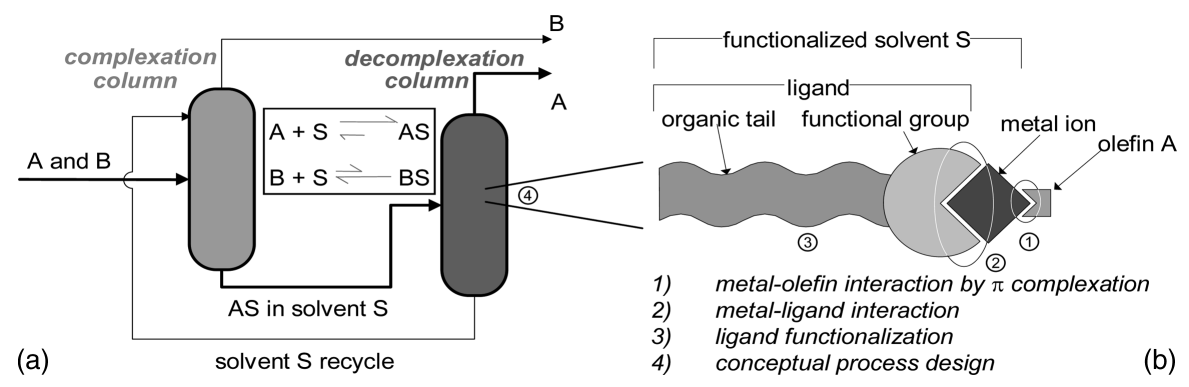

Figure 1. Schematic representations of Reactive Extractive Distillation using functionalized solvent S (a), a complex of the metal-ligand solvent with the (desired) olefin (b) and the four topics addressed in this paper

and paraffins. The effect of structure and size of the organic tail of these ligands, and the influence of temperature and pressure is also discussed.

4. Conceptual design of the recovery of 1-hexene from a complex Fischer-Tropsch mixture by Reactive Extractive Distillation (complexation and decomplexation).

\section{EFFECT OF OLEFIN ISOMER STRUCTURE ON $\boldsymbol{\pi}$ COMPLEXATION}

The effect of the olefin structure on the $\pi$-complexation with silver is investigated by its reactive sorption in a solution of silver nitrate in ethylene glycol. The presence of silver nitrate increases the olefin solubility in ethylene glycol because of its $\pi$-complexation reactions with silver. The selectivity may increase due to differences in the complexation ability of the various olefins. Of the tested mono-olefins, 1-hexene has the highest complexation constant. However, the overall largest increase is measured for the diolefin 1,5-hexadiene. The results indicate that all olefins form $1: 1$ (silver:olefin) complexes, but that 1-hexene also produces $1: 2$ complexes whereas 1,5 -hexadiene also forms $2: 1$ complexes. The differences in complexation ability are due to steric hindrance, which is mainly reflected in the entropy change of complexation for the mono-olefins. Thus, $1: 1$ complexes with mono-olefins exhibit an equal change in enthalpy of complexation $(15.5 \mathrm{~kJ} / \mathrm{mol})$. For the di-olefin 1,5-hexadiene it is larger $(22 \mathrm{~kJ} / \mathrm{mol})$ as both double bonds are involved in the complexation. The vapour-liquid selectivity for most C6-olefin isomers relative to 1-hexene i.e. the ratio of distribution coefficients ( $\mathrm{D}_{\text {isomer }} /$ $\mathrm{D}_{1 \text {-hexene }}$ ) is increased due to the complexation: 4.9 for trans-2-hexene, 1.8 for 2-methyl-1-pentene, 1.3 for cis-2-hexene and 0.4 for 1,5-hexadiene. Only the separation of 1-methylcyclopentene appeared problematic as the selectivity is only 0.9 . The results show a strong relation between the complexation strength and the stoichiometry of complexation. In most instances the achieved selectivities are sufficient to separate 1-hexene from the other isomers.

The capacity and selectivity may alter in a multi-component mixture of olefin isomers through changes in the physical solubility and competition between these 


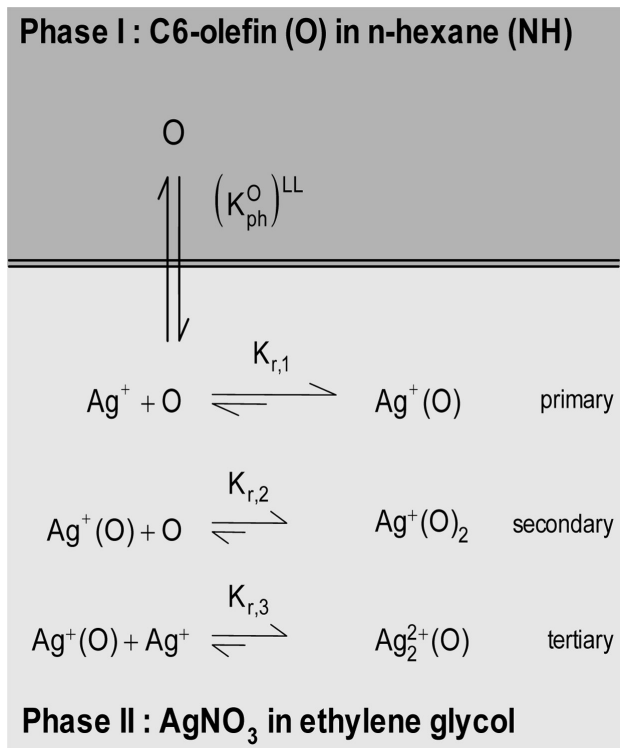

Figure 2. C6-olefin solubility at equilibrium in a (reactive) solvent

Table 2. Complexation constants at various temperatures and associated entropy and enthalpy changes for primary complexation of 2-methyl-1-pentene, 1-methylcyclopentene, cis-2-hexene and trans-2-hexene, primary and secondary complexation for 1-hexene) and primary and tertiary complexation for 1,5-hexadiene

\begin{tabular}{|c|c|c|c|c|c|}
\hline & \multicolumn{3}{|c|}{$\mathrm{K}_{\mathrm{r}, 1}(\mathrm{l} / \mathrm{mol})$} & \multirow{2}{*}{$\begin{array}{c}\Delta \mathrm{S}_{\mathrm{r}} \\
\mathrm{J} \mathrm{mol}^{-1} \mathrm{~K}^{-1}\end{array}$} & \multirow{2}{*}{$\begin{array}{c}\Delta \mathrm{H}_{\mathrm{r}} \\
\mathrm{kJ} \mathrm{mol}^{-1}\end{array}$} \\
\hline & $300 \mathrm{~K}$ & $308 \mathrm{~K}$ & $323 \mathrm{~K}$ & & \\
\hline cis-2-hexene & $4.64 \pm 0.06$ & $4.02 \pm 0.06$ & $3.0 . \pm 0.03$ & $-39 \pm 2$ & $-15.5 \pm 0.7$ \\
\hline 2-methyl-1-pentene & $3.43 \pm 0.04$ & $2.83 \pm 0.03$ & $2.02 \pm 0.04$ & $-42 \pm 2$ & $-15.5 \pm 0.7$ \\
\hline 1-methycyclopentene & $2.68 \pm 0.05$ & $2.25 \pm 0.04$ & $1.47 \pm 0.02$ & $-44 \pm 2$ & $-15.5 \pm 0.7$ \\
\hline $\begin{array}{l}\text { trans-2-hexene } \\
\text { 1-hexene }\end{array}$ & $1.23 \pm 0.03$ & $1.02 \pm 0.02$ & $0.76 \pm 0.01$ & $-50 \pm 2$ & $-15.5 \pm 0.7$ \\
\hline $\mathrm{K}_{\mathrm{r}, 1}(\mathrm{l} / \mathrm{mol})$ & $6.5 \pm 0.5$ & $5.8 \pm 0.3$ & $4.2 \pm 0.1$ & $-36 \pm 2$ & $-15.5 \pm 0.7$ \\
\hline $\begin{array}{r}\mathrm{K}_{\mathrm{r}, 2}(\mathrm{l} / \mathrm{mol}) \\
1,5 \text {-hexadiene }\end{array}$ & $3.9 \pm 0.8$ & $2.4 \pm 0.6$ & $1.9 \pm 0.3$ & $-79 \pm 38$ & $-27 \pm 12$ \\
\hline $\mathrm{K}_{\mathrm{r}, 1}(\mathrm{l} / \mathrm{mol})$ & $63 \pm 4$ & $58 \pm 5$ & $32 \pm 1$ & $-38 \pm 24$ & $-22 \pm 8$ \\
\hline $\mathrm{K}_{\mathrm{r}, 3}(\mathrm{l} / \mathrm{mol})$ & $1.1 \pm 0.2$ & $0.9 \pm 0.3$ & $0.6 \pm 0.1$ & $-76 \pm 10$ & $-23 \pm 3$ \\
\hline
\end{tabular}


isomers for metal ions. Indeed a lower solubility was found for both 1-hexene and 2-methyl-1-pentene in a binary mixture. But, the selectivity remains unaffected.

\section{SCREENING AND SELECTION OF METAL-LIGAND COMPLEXES IN GRAVIMETRIC ANALYSER}

To study the olefin solubility in a reactive solvent a gas absorption method using microvolumes was developed. The procedure in this Intelligent Gravimetric Analyser (IGA) comprises in situ degassing of the solvent, sample mass stabilisation due to evaporation and automated measurement of absorption isotherms. Applying metal-ligand complexes based on commercially available ligands developed in the hydrometallurgy can increase the selectivity of olefin isomer separation, increase capacity and metal-ion stability and reduce energy costs relative to highly polar solvents such as ethylene glycol. This is investigated by extracting silver from aqueous solutions using different ligands (Table 3 ) and gravimetrically measuring the ethylene solubility of the metal-ligand organic solution. $\mathrm{C}_{2} \mathrm{H}_{4}$ is used because from all olefins it shows the strongest interaction.

The measurements show a qualitative relation between stability and the ability of the metal-ligand complex. The stability of a complex is quantified by the ease of extracting silver from an aqueous solution. Two extractants, LIX 26 and LIX 54 do not easily extract silver but its extraction can be enhanced by adding $\mathrm{NaOH}$. Nevertheless, the resulting metal-ligand complex is unstable because silver precipitates from the solution. In contrast, Cyanex 301 and 302, thio phosphoric acids, do not require $\mathrm{NaOH}$ and easily extract silver from solution.

The sulphur bonds directly with silver, whereas the metal-ligand is stable, but the silver-ion is no longer able to complex with ethylene: it has lost its ability to form $\pi$ complexes, resulting in linear sorption isotherms, see Figure 3. Two other ligands, di(2-ethylhexyl)phosphoric acid (D2EHPA) and di-nonyl naphthalene sulphonic acid (DNNSA) also require the addition of $\mathrm{NaOH}$ to extract silver but in smaller amounts as LIX 26 and 54, resulting in a stable metal-ligand complex. With both ligands the presence of silver almost triples the ethylene solubility compared to the solvent without silver, see Figure 4. The silver-D2EHPA complex could complex a single ethylene molecule whereas silver-DNNSA can complex two ethylene molecules. This can be explained by the stoichiometry between metal and ligand, DNNSA and silver form 1:1 complexes, while D2EHPA forms a 1:2 complex (metal:ligand). The presence of these two ligands on a single silver atom restricts its accessibility for ethylene.

\section{EFFECT OF LIGAND STRUCTURE ON REACTIVE VAPOUR-LIQUID SELECTIVITY FOR OLEFIN ISOMERS}

Vapour-liquid equilibrium experiments are performed to evaluate the suitability of the successfully developed $\pi$-complexating silver-ligand complexes for application as functionalised solvent in Reactive Extractive Distillation to separate 1-hexene from other $\mathrm{C}_{6}$-olefin isomers. Three different phosphoric acid ligands: di (2-ethylhexyl) phosphoric acid (D2EHPA), di (butyl) phosphoric acid (DBPA) and mono (2-ethylhexyl) phosphoric 


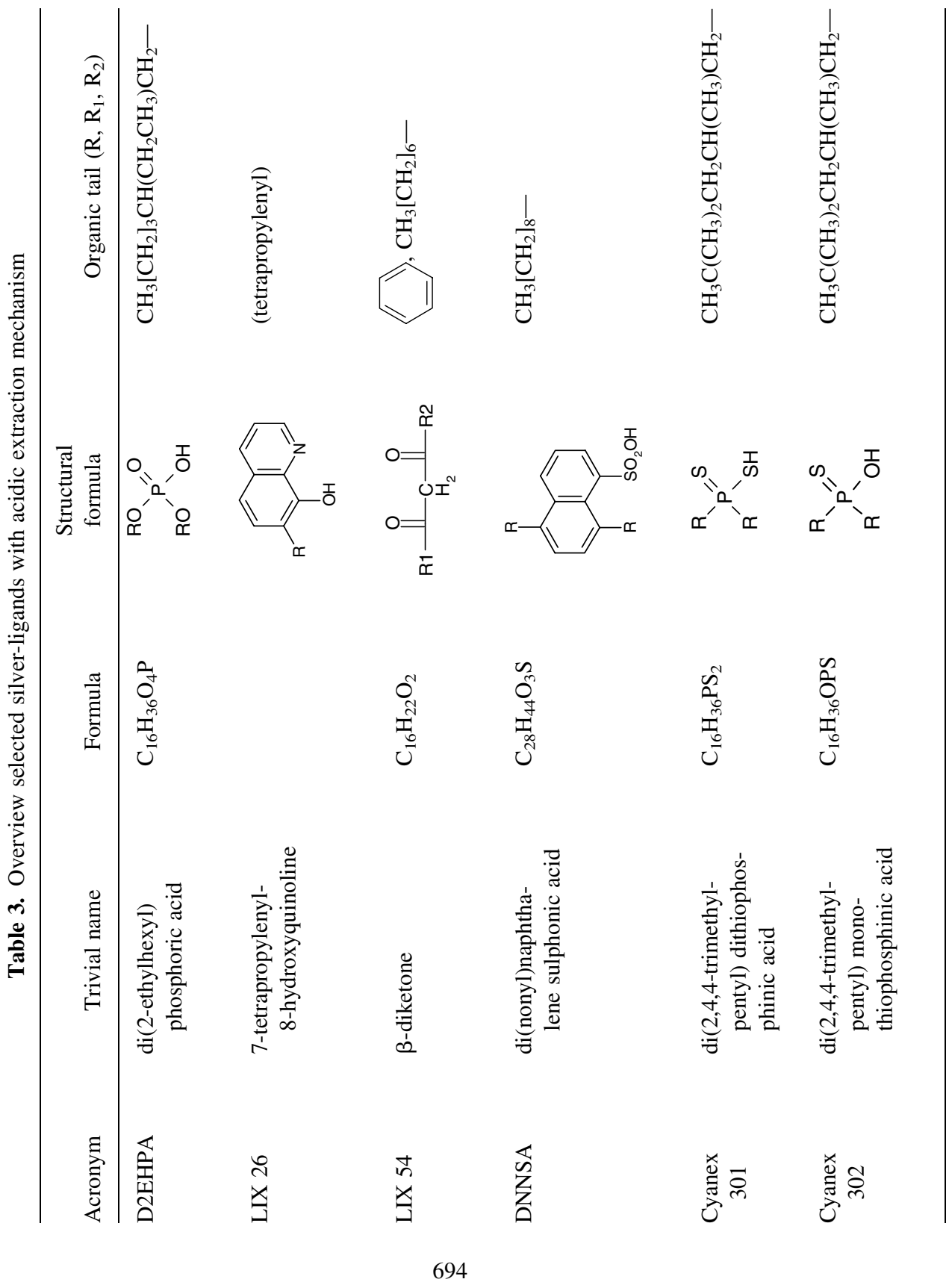




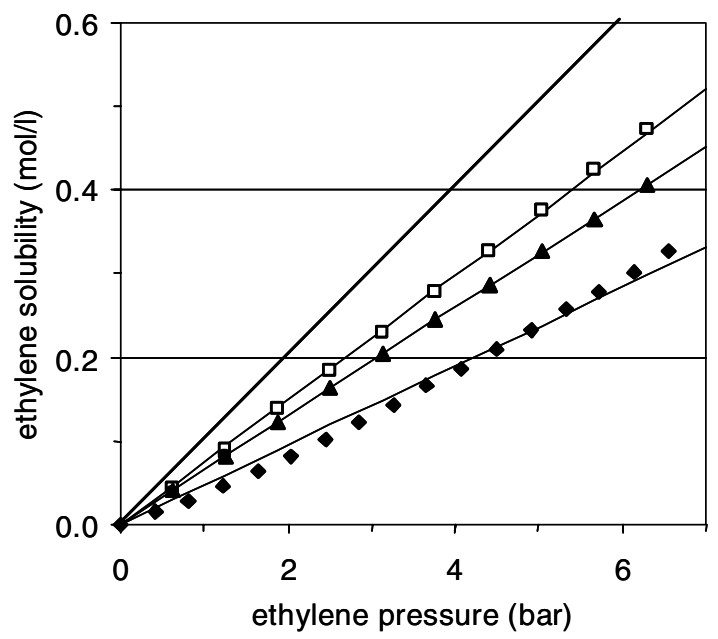

Figure 3. $\mathrm{C}_{2} \mathrm{H}_{4}$ solubility in solution of Cyanex 301 or 302 in dodecane with(out) Ag at $298 \mathrm{~K}$.

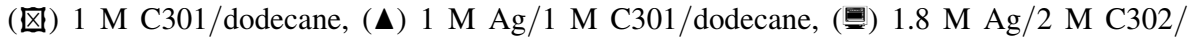
dodecane, $(-)$ pure dodecane

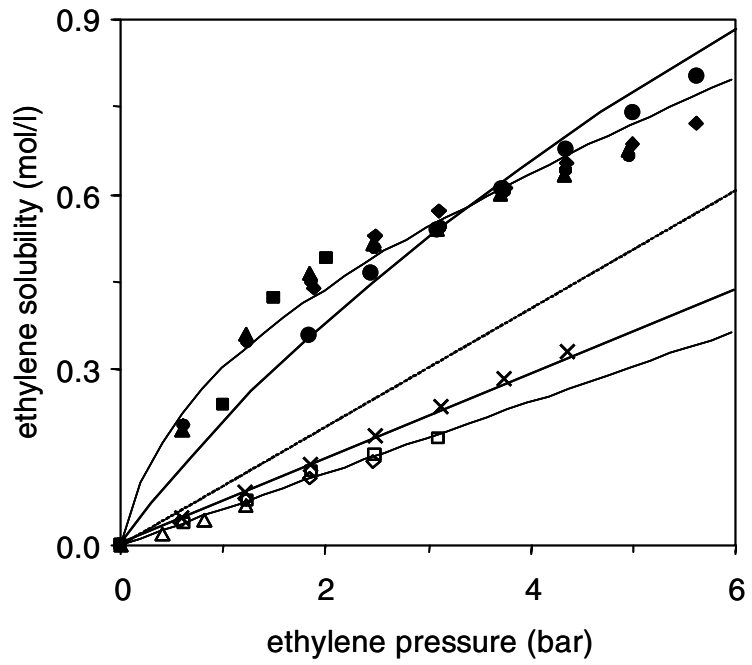

Figure 4. $\mathrm{C}_{2} \mathrm{H}_{4}^{-}$solubility in solution of D2EHPA or DNNSA in dodecane with(out) Ag at $298 \mathrm{~K}$. (•) $0.8 \mathrm{M} \mathrm{Ag} / 2 \mathrm{M}$ D2EHPA/dodecane,(6) $0.8 \mathrm{M} 2 \mathrm{M}$ D2EHPA/ dodecane,

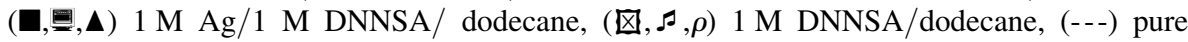
dodecane 
acid (MEHPA) and two sulphonic acid ligands: di nonyl naphthalene sulphonic acid (DNNSA) and dodecyl benzene sulphonic acid (DBSA), were investigated for a variety of $\mathrm{C}_{6}$-olefin isomers (1-hexene, 2-methyl-1-pentene, n-hexane, 1,5-hexadiene, trans2-hexene), see Figure 5.

Independent of the solvent (complex) a selectivity of 1.02 for 2-methyl-1-pentene/ 1-hexene was obtained without silver. The selectivity for $n$-hexane/1-hexene in absence of silver depends on the solvent polarity and was just below unity. The presence of silver in the solvent increases both selectivities. At equal silver concentration the ligand size does not influence the selectivity of chemically similar components (1-hexene/2-methyl1-pentene). However, the selectivity between chemically different components (1-hexene/n-hexane) is increased by a smaller ligand because it is more polar. Lowering the equilibrium pressure results in a lower boiling temperature, thereby increasing the complexation constant and therefore the selectivity.

A higher silver concentration and a higher solvent-to-feed ratio $(S / F)$ both increase the availability of silver and thus the selectivity. The highest selectivities were obtained for silver-DBPA (20 wt $\% \mathrm{Ag}, S / F=3$ ): 1.23 for 2-methyl-1-pentene and 1.42 for n-hexane.

\section{CONCEPTUAL DESIGN OF REACTIVE EXTRACTIVE DISTILLATION COLUMN FOR C6-OLEFIN ISOMERS}

A thermodynamic model is used to conceptually design a Reactive Extractive Distillation column (Figure 1a) based on the developed metal-ligand technology applying the functionalised solvent silver-D2EHPA. Column and operational parameters are obtained based on experiments for a wide range of $S / F$. The maximum selectivity with respect to 1-hexene that can be obtained with Ag-D2EHPA is 1.45 for 2-methyl-1-pentene and 1.94 for n-hexane at $S / F=17$ ( $p=0.2$ bar). At higher $S / F$ the selectivity decreases because of a higher equilibrium temperature, see Figure 7. For a desired 1-hexene recovery of $99 \%$ and $99.5 \%$ purity, the Reactive Extractive Distillation system may be operated at $S / F \approx 5(p=0.2$ bar, $T=311 \mathrm{~K})$. The resulting selectivities are 1.34 (2-methyl1-pentene/1-hexene) and 1.55 (n-hexane/1-hexene). If so, the minimum number of equilibrium trays $\left(N_{\min }\right) \approx 42$, a dramatic decrease compared to $N_{\min } \approx 310$ in absence of silver.

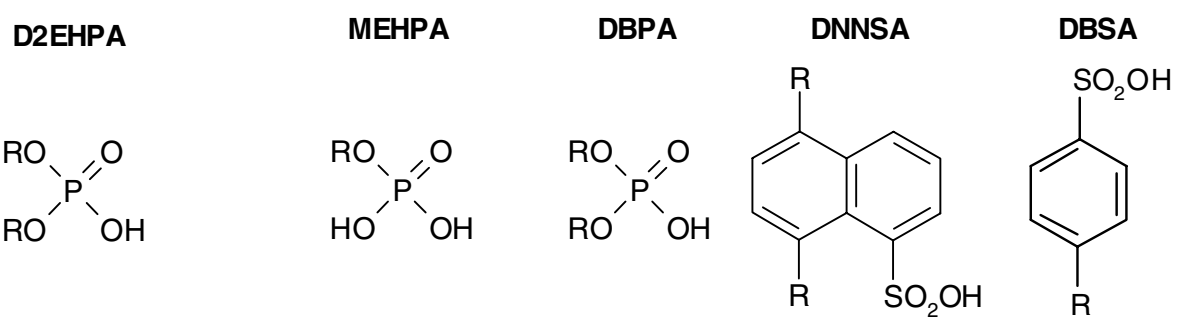

Figure 5. Investigated ligands in VLE experiments with corresponding R-group 

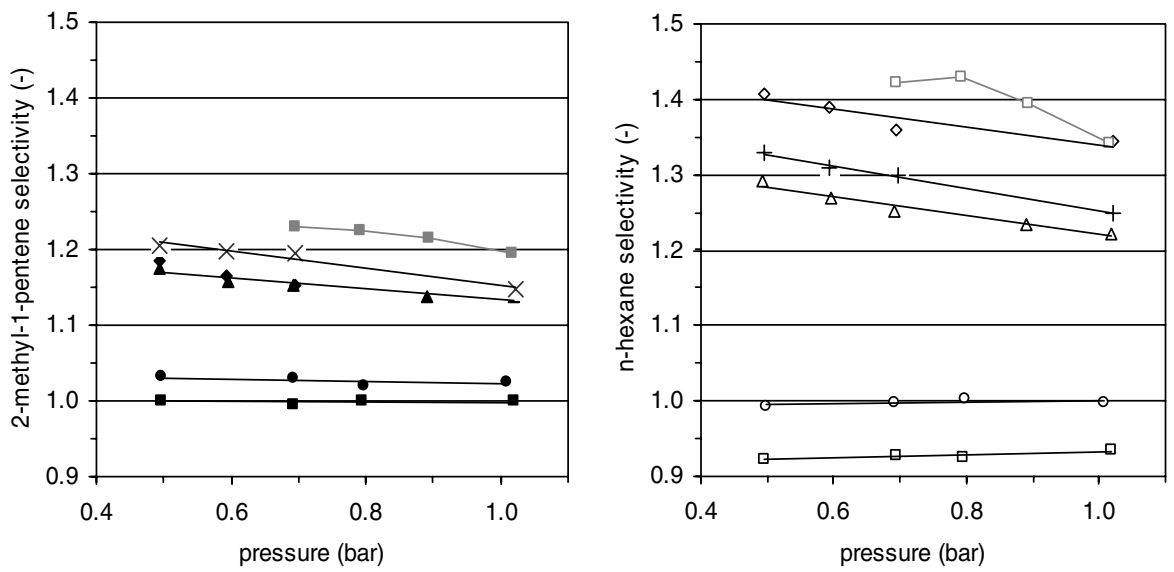

Figure 6. Comparison of the selectivity relative to 1-hexene for n-hexane $(\mathrm{NH})$ and 2-methyl1-pentene (2M1P) for DBPA, DNNSA and D2EHPA at S/F-ratio of 3 with approximately the same amount of silver ( $\square, \bigotimes)$ D2EHPA physical, ( $\star$,, DBPA physical, $(\pi, \rho)$ Ag-D2EHPA

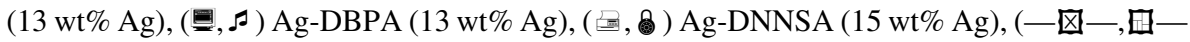
) Ag-DBPA (20 wt $\% \mathrm{Ag}$ ). The lines are trend lines
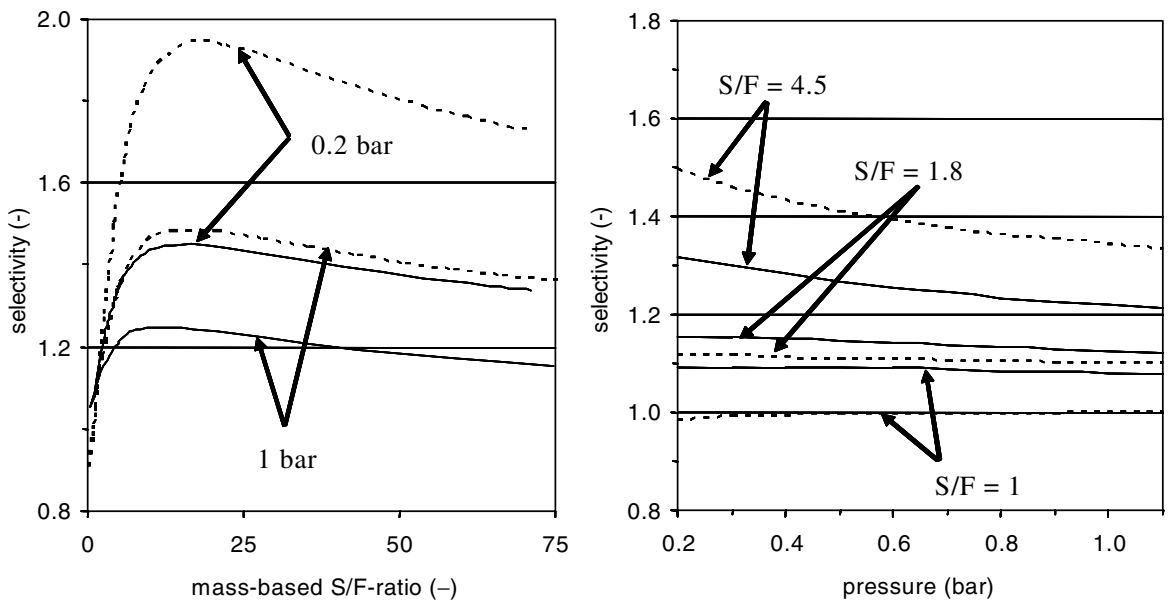

Figure 7. Selectivity relative to 1-hexene as function of the mass-based solvent to feed ratio (S/F) (left) and pressure (right) as predicted by the model. Specified liquid composition AgD2EHPA plus $n$-hexane/2-methyl-1-pentene/1-hexene in a 1/1/2 ratio, (-- ) selectivity n-hexane/1-hexene, (一) selectivity 2-methyl-1-pentene/1-hexene 


\section{CONCLUSION}

The use of functionalised metal-ligand solvents is promising to drastically improve olefin separations by RED.

\section{ACKNOWLEDGEMENT}

The authors thank Sasol and NWO (Dutch Science Foundation) for the financial support of this work, Henny Bevers for his assistance in the performed analysis, and Hiden Analytical for the technical assistance.

\section{REFERENCES}

1. Wentink, A.E., Kuipers, N.J.M., de Haan, A.B., Scholtz, J., Mulder, H., Synthesis and evaluation of metal-ligand complexes for selective olefin solubilization in reactive solvents, Ind. Eng. Chem. Res. 44 (13), 4726-4736 (2005).

2. Wentink, A.E., Kuipers, N.J.M., de Haan, A.B., Scholtz, J., Mulder, H., Effects of ligand structure on reactive vapor-liquid distribution ratio and selectivity for C6-olefin isomers, Ind. Eng. Chem. Res. 44 (24), $9221-9229$ (2005).

3. Wentink, A.E., Kuipers, N.J.M., de Haan, A.B., Scholtz, J., Mulder, H., Synthesis, Effect of C6-olefin isomers on $\pi$-complexation for purification of 1-hexene by reactive extractive distillation, Separation and Purification Technology 43, 149-162 (2005).

4. Wentink, A.E., Functionalised solvents for olefin isomer purification by reactive extractive distillation, PhD Thesis, University of Twente, The Netherlands (2004). 